\title{
Research of the backing technology of the book block spine
}

\section{ABSTRACT}

The factors influencing the backing process of the book block spine are determined and their priorities are established. The method of backing the spine of book blocks in the production of publications by the method of perfect binding is proposed. This method involves gluing the backing-captal braid to the spine of the block with a pre-applied adhesive layer. The positive influence of the presence of the adhesive layer of a certain thickness on the physical and mechanical characteristics of the backing material is determined. It is established that the thickness of the blocks, the type of paper, from which the publications are made, and the direction of the cutting of the backing material is influenced by the process of backing the spine. With the growth of the tension deformation of backing materials from 1.2\% (for kraft paper) to $3.8 \%$ (for the backing braid), the stability of the spine zone of the block increases to damage in the process of multiple flippers. The investigated materials in the longitudinal direction are more durable than in the transverse in 2-2.5 times, so the backed blocks can withstand 4,800 to 15,000 flippers when using kraft paper and backing braid, respectively. With the help of optical microscopy, changes in the structure of the backing-captal braid after the multiple flippers of the book block have been investigated. It is shown that the strength of the binding of a book block depends on the choice of the method of backing. In the process of optimizing the parameters of backing the block root, various variants of linear models were tested, which are described by the functions of the dependences of the breaking forces in the longitudinal or transverse directions $Z$ on the thickness of the block Tb. The allowable elongation of the edging material for its longitudinal and transverse cutting $V$ is also taken into account. The obtained models allow for the particular type of paper to pick up the necessary backing materials, which will provide a sufficient strength to the perfect binding book blocks.

\author{
Svitlana Havenko ${ }^{1}$ \\ Iryna Pikh ${ }^{2}$ \\ Lyubomyra Kulik ${ }^{2}$ \\ Ivanna Konyukhova ${ }^{2}$ \\ Raisa Rybka ${ }^{2}$ \\ Olha Vorzheva ${ }^{2}$ (1)
${ }^{1}$ Lodz University of Technology, Lodz, Poland \\ ${ }^{2}$ Ukrainian Academy of Printing, \\ Lviv, Ukraine
}

\section{Corresponding author: \\ Svitlana Havenko \\ e-mail: \\ svitlana.havenko@p.lodz.pl; havenko1559@gmail.com}

First recieved: 27.7.2019.

Accepted: 23.12.2019.

\section{KEY WORDS}

The spine of book block, backing materials, adhesives, strength of fastening

\section{Introduction}

Adhesive binding is widely used in the production of counterfoil edging of books in modern technology. This method allows relatively easy mechanization and automation of production processes. System engineering analysis has found that perfect binding books have insufficient strength of sheets fastening in blocks, which causes partial destruction of the spine and dropping of sheets when using them. Thus, in (Petriaszwili \& Pyrjew, 2008), it is indicated that significant influence on the quality of perfect binding publications has the methods of processing of blocks spine before glue applying. The analysis of models of adhesive interaction of glues and papers depending on the technology of spine processing is presented. Researchers (Havenko et al., 2018a) of per- 
fect binding technology are studying the change in the stress-strain state of books in the process of exploitation. The influence of the physical and mechanical properties of adhesives, the method of their applying on the blocks spine and the binding process is considered in (Havenko et al., 2018b). New devices are being developed to improve the process of gluing the spine of blocks at perfect binding (Polit, Snowden \& Watson, 1974). Researchers emphasize the need to choose a method of processing the spine of the block with a special cutting tool. The authors (Rabinovich, 1998) suggest a modified method of gluing and additional processing of the spine to strengthen the spine zone of the book blocks. A detailed analysis of the practical problems of bonding the spine of blocks in the production conditions is given in (Kolpakova, 2003).

The technology of processing the spine of book blocks with disk knives inclined at an angle to them, the question of experimental measurement and quantification of torque is considered in the paper (Knysh, 2013).

Modern technology of book production uses a variety of adhesives for perfect binding of sheets in the block. In recent years, it widely used dispersion, polyurethane and hot melt adhesives. Work (Palyuk, 2018) dedicated to study the glueing ability of certain types of adhesives for the production of book frames from binder materials with different technological properties. The influence of the structure of materials on the formation of adhesive seams and the cohesion strength of bonding the spine of the book block is investigated in (Gromyko \& Marchenko, 2018). The however, often-existing adhesives cannot meet the requirements of consumers regarding the strength of the binding of book blocks. Therefore, it is necessary to improve the technology of producing publications in the way of perfect binding. Moreover, one of them is backing of the spine of blocks of special materials.

The operation of backing the book blocks is often considered only in terms of increasing the strength characteristics of individual parts and units of the finished book. However, backing is also a kind of protective element that facilitates the execution of technological operations in the processing of blocks (rounding, bending folds). With the help of the backing of book blocks, the connection between the endpaper and the internal sheets of the extreme folded sheet of the block is strengthened (especially in the presence of frontispieces). The also strengthens the connection between the first and last sheets of folded sheet with the block. All this increases the strength of the block connection with the binder.

In the role of a protective element, the backing has a dual purpose. Firstly, it protects the fold of the endpaper and the bending of the outer sheets of the extreme folded sheets from the action of the mechanisms of rounding and lamination of the spine of the block. At the same time, the probability of endpapers tearing off when gluing in the casing-in machine disappears. Secondly, it protects the endpaper and the outer sheets of the extreme folded sheets of the block from getting glue when gluing the gauze and the captal-paper strip when inserting the block into the cover. The quality of backing depends on the technology of the process, the use of appropriate backing materials, the perfection of the design of backing machines or mechanisms.

Therefore, the actual task for improving the strength of the spine part of the block and increasing the durability of the publication is to improve the technology of backing the spine of the book block with the use of technological variants of gluing it to the backing material.

\section{Analysis of literature and problem statement}

The known ways of backing the book blocks can be classified according to the principle of performance of technological operations, the type of backing material (roll, tape of a certain format), the method of joining it to the spine (without glue, with pre-applied glue, thermal pressure). Additional strengthening of the block is achieved by backing the spine with a stronger material (for example, gauze, duplicated with paper or cloth trimmed with hot glue). The researchers (Anon, 1998) recommend to backing of extreme folded sheets with non-woven material with a $20 \mathrm{~mm}$ output of it on endpaper. This can provide a high strength connection of the block with cover without using any other spine material. The strength of books made on this technology is practically not inferior to the strength of books sewn on gauze. The industrial application of this method is complicated by the impossibility of equipping existing models of folding machines with sewing apparatus for framing the spine-field of the folded sheet at the place of the last fold. The importance of mechanizing the treatment of the spines of perfect binding blocks, the process of backing to activate the formation of a strong gluing adhesive connection is considered in (Petrie, 2008).

The analysis of scientific publications shows that the attention of scientists is attracted by the problems of intensifying the processes of backing the spines of book blocks, fastened threads, thermo threads with the use of various materials (Stachowicz, 2013a). The paper (Stachowicz, 2013b) describes studies of determining the energy absorption criterion for backing materials recommended for strengthening the spine of the book block. Studies of the structure of materials, their mechanical characteristics for backing the spines of the block are given in (Bubela \& Shabliy, 2016). An analysis 
of modern technologies for the production of printed publications has shown that the backing of the spines of perfect binding blocks with special material has all the prerequisites for becoming the main in brochure and cover production. After all, this process reduces the cost of making books, while providing increased strength of block fastening and durability of products.

Therefore, it is relevant to study the technological process of backing the book block of perfect binding, which involves applying glue to the spine, sticking to it in three places: on the edges and in the middle of the backing-captal braid (Havenko et al, 1998).

\section{The purpose and objectives of the research}

The aim of the research is to improve the process of backing the book blocks of perfect binding with backing materials with different deformation properties.

To achieve this aim, the following tasks were set:

- to study the influence of physical and mechanical properties of backing materials on the strength of the spine part of the block;

- to simulate the discontinuous efforts and to pull out a sheet of backed book blocks made of offset and coated paper to determine the optimal performance indicators of the perfect binding publications.

\section{Materials and methods of studying the processes of backing the spines of book blocks}

\section{Investigated materials and equipment used in experiment}

The objects of research were selected book blocks made of offset paper Megga matt (weight $80 \mathrm{~g} / \mathrm{m} 2$, degree of gluing $0.75 \mathrm{~mm}$ ) and coated paper Galeri Art (weight $90 \mathrm{~g} / \mathrm{m} 2$, degree of gluing $1.25 \mathrm{~mm}$ ). The composition of these papers includes a variety of fillers, which complicates the depth of penetration of glue and slow down the process of fixing adhesive film to the spine of the block. This leads to a decrease in the performance indicators of book publications. Polyurethane adhesive and hot melt adhesives were used for fastening and backing the spines of the blocks (size blocks - 100x150 $\mathrm{mm}$ ). For research was made 11 identical samples of book blocks. To strengthen the spine part of the block, a backing-captal braid, a printing gauze (density 15 threads/cm) and kraft paper Swan White, the characteristics of which are shown in Table 1, were used.

Backing the glued spines of the blocks was carried out in the layout of the developed device, the scheme of which is shown in Figure 1.

The layout consists of two parts. The first part includes a device for gluing the spines of the blocks. The gluten bath is easily removable, with hole for pouring glue. The squeegee system on the glued-up roller ensures uniform application of glue strips to the endpaper, width of 5 to $18 \mathrm{~mm}$, with a layer thickness of $0.2 \mathrm{~mm}$. The guides 1 of the device through the adhesive bath 3 move the book block 2 in a clamped state with a spine down.

\section{Table 1}

Characteristics of backing materials

\begin{tabular}{|c|c|c|c|c|c|c|}
\hline \multirow{3}{*}{$\begin{array}{l}\text { Type of } \\
\text { material }\end{array}$} & \multicolumn{6}{|c|}{ Technological indicators } \\
\hline & \multirow{2}{*}{ Density, $\mathrm{g} / \mathrm{m}^{2}$} & \multirow{2}{*}{$\begin{array}{l}\text { Thickness, } \\
\text { microns }\end{array}$} & \multicolumn{2}{|c|}{ Longitudinal direction of cutting } & \multicolumn{2}{|c|}{ Transverse direction of cutting } \\
\hline & & & $\begin{array}{l}\text { Breaking } \\
\text { effort } \mathrm{N} / \mathrm{cm}\end{array}$ & $\begin{array}{c}\text { Relative } \\
\text { elongation, \% }\end{array}$ & $\begin{array}{l}\text { Breaking } \\
\text { effort N/cm }\end{array}$ & $\begin{array}{c}\text { Relative } \\
\text { elongation, \% }\end{array}$ \\
\hline $\begin{array}{l}\text { Backing- } \\
\text { captal braid }\end{array}$ & $100-110$ & 90 & 20.6 & 2.6 & 12.5 & 10.2 \\
\hline $\begin{array}{l}\text { Printing gauze } \\
\text { (density } 15 \\
\text { threads/cm) }\end{array}$ & 190 & 50 & 15.1 & 2.9 & 9.8 & 8.95 \\
\hline $\begin{array}{l}\text { Kraft paper } \\
\text { Swan White }\end{array}$ & $75-80$ & 109 & 14.8 & 2.5 & 8.45 & 7.1 \\
\hline
\end{tabular}


Then the block enters the backing operation. The backing device consists of a rail 4 , on which the block moves, with the spine of the bottom, and three coils 5 with a braid 6 . The backing braid is applied to the guides in three places of the block (in the upper, lower and middle). The width of the braid is selected depending on the height of the block. The remainder of the braid cuts off the knife 7, which moves through the handle 8 , after fixing the braid on the spine of the block in the appropriate places. The backed block in the clamped state is output from the device.

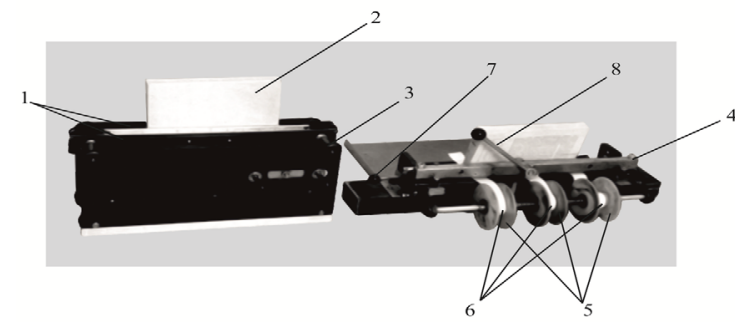

» Figure 1: A model of the developed device for gluing and backing of the spines of book blocks with backing-captal braid: 1- guides; 2 - book block; 3 - an adhesive bath; 4 - rail; 5 - coils; 6 - backing-captal braid; 7 - knife; 8 - fixation handle (Havenko et al, 1998)

\section{Methods of studying the physical and mechanical properties of backing materials and performance indicators of backed book blocks}

The deformation properties of the backing material were determined on a discontinuous (upgraded) RMP-50 machine and a DFC falscher. To determine the deformation characteristics of backing materials, an elastomer of the design of Y. Chekhman was used. Structural transformations in backing materials were investigated by optical microscopy by microscope MI-8 (Fischer \& Naber, 2006)

Characteristics of glue connections at the spine of the book blocks were determined by studying the effort to pull out the sheet from the block, the effort of breaking the book block and the resistance to multiple flippers. The strength of the backed book blocks was researched on the Zihloch testers (Germany). The stability of adhesive connections to multiple flippers was determined by the Flex-Test method, and the durability of the sheet-breaking, characterizing the durability of publications, by the Pull-Test method according to the standard methodology. For each testing methods of research (Pull-Test, Flex-Test, tensile test) seven identical samples of $100 \times 150 \mathrm{~mm}$ book blocks were used to confirm the accuracy of the measurement results. The optimization of the process of backing the spines of book blocks was carried out using the Maple package for the developed program (Dyakonov, 1998). It took into account a statistical sample of experimentally determined characteristics of the backed materials, the thickness of the blocks, the size of the discontinuous efforts and the efforts of pull out the sheets from the blocks.

\section{Investigation of the influence of physical and mechanical characteristics of backing materials on the strength of the spine part of the book block}

Investigation of the durability of the backing material (by the number of double flippers) shows that all materials in the longitudinal direction are more durable than in the transverse. Studies have confirmed that the kind of edging material influences the stability of book blocks to double flippers. The book blocks edged with kraft paper stand 2490 flippers, edged with printing gauze- 2680 and edged backing braid- over 3000 flippers. Moreover, in the backing braid during the testing period, there was no significant structural change, as evidenced by optical microscopy (Figure 2).

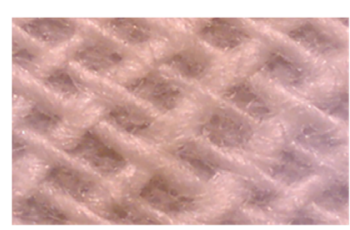

a)

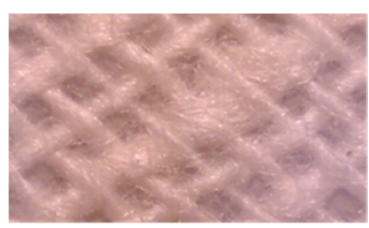

b)
» Figure 2: Microphotography of the structure of the backing-captal braid: a - before double flippers on the testers; $b$ - after testing

The analysis of the microphotographs showed that the fibers of the backing braid interlaced at an angle close to $45^{\circ}$, forming a structured form of cells and pockets that are uniformly filled with glue. This structure promotes the formation of strong ties in the system of paper-glue-backing braid, firmly strengthening the spine of the book block.

It is known that when gluing the spines of the block, a film is formed, the physical and mechanical properties of which significantly affect the strength and quality of fastened sheets. When using the book, the spine film bends and each element of the design, obviously, has a different effect on the deformation of the film. Therefore, it is important to study the optimal conditions for the discovery of blocks with different thickness of the adhesive film in the spine of the block, which consists of the adhesive layer and the thickness of the backing-captal braid. Adhesive film and backing-captal braid have a different magnitude of relative elongation. It has been experimentally established that the relative elongation of the polyurethane adhesive film is $550 \%$, and the relative elongation of the backing-captal braid is only 

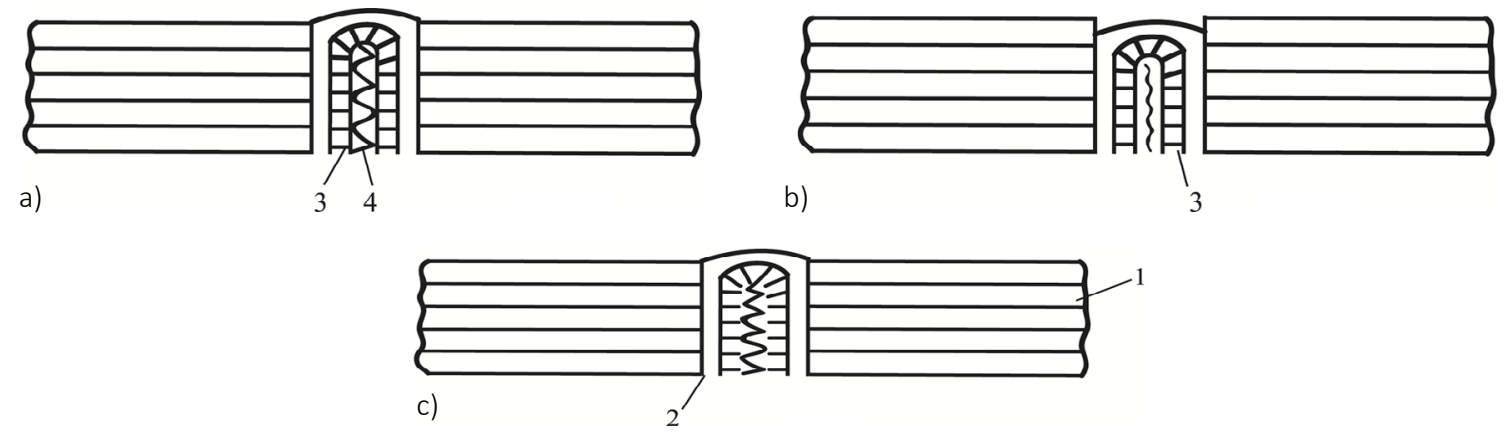

» Figure 3: Model positions of the spine part of the publication, fastened with glue and backing by a backing-captal braid: $a$-stretch of adhesive film; $b$ - separating the glue film from the sheets; $c$ - partial gap of the top of the adhesive film; 1 - sheets; 2 -adhesive layer; 3 - backing-captal braid; 4 -adhesive layer over the backing-captal braid

$6.5 \%$ on the basis and by the duct diagonally- $12.9 \%$. The research considered variants when the adhesive film was applied on top and bottom of the braid (Figure 3).

In the process of opening the book when placing a backing material on top, the adhesive film or stretch (Figure $3, a$ ), or there is a partial break of its upper part (Figure $3, c)$. The latter case occurs when the adhesion exceeds the strength of the film and its elongation exceeds the limit value. In blocks with backing-captal braid from below, the reinforced film is separated from the sheets (Figure 3, b). At the same thickness of the adhesive film with the growth of the thickness of the spine material, the size of the split block increases. In the blocks, glued by the backing-captal braid from below, the size of the splitting is not much different from the size of the split blocks, backed with a braid above. But the character of the split is different- the edges of the sheets in greater degree are separated from the spine film, that is, the larger value of the separation. When the block is opened, the edges of adjacent sheets are removed from each other by a value that far exceeds the distance between the sheets in the spine of the closed block. This phenomenon can cause elongation of glue film and spines of the backing material. In addition, the deformation properties of the same backing material are influenced by glues. So polyurethane adhesives improve the properties of the substrate. Within the relative extension of the backing materials, a decrease in their deformation is ensured, and at the same stress, the substrate uncoated with the adhesive deforms much more (Figure 4). a)

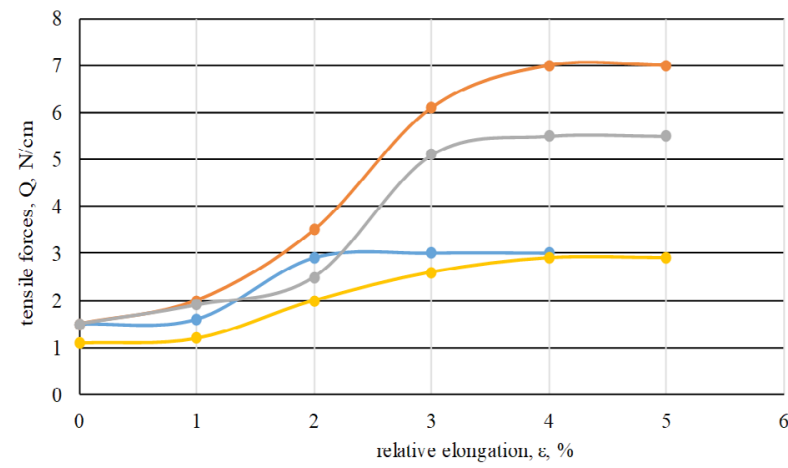

b)

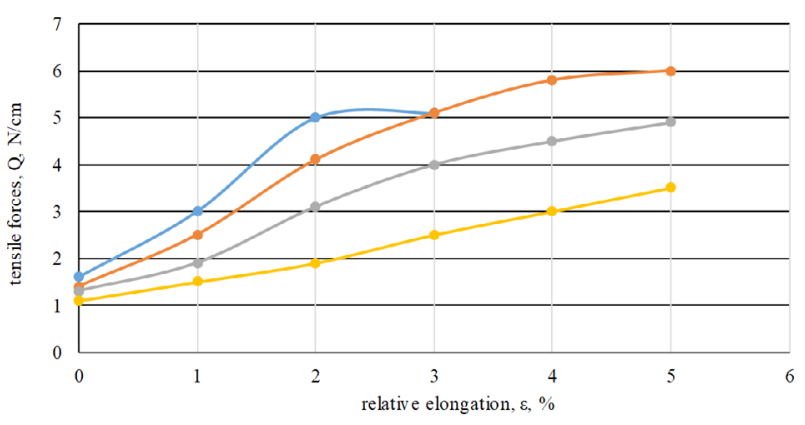

$\rightarrow$ l-without glue

$\rightarrow-2$-with a gluc laycr of thickness - $1 \mu \mathrm{m}$

-3 -with a glue layer of thickness - $2 \mu \mathrm{m}$

$\rightarrow-4$-with a glue layer of thickness $-3 \mu \mathrm{m}$

» Figure 4: Change of deformation properties of backing-captal braid with one axial stretch: without glue (1); with a glue layer of thickness - $1 \mu \mathrm{m}$ (2); $2 \mu \mathrm{m}$ (3); $3 \mu \mathrm{m}$ (4); $a$ - longitudinal direction; $b$ - transverse direction 
Studies have shown that there are changes in the deformation of the backing materials, depending on the direction of cutting. In the longitudinal direction, the cutting significantly increases the resistance to multiple flippers in kraft paper and printing gauze. The backing-captal braid undergoes slight changes with one axial stretch (in the transverse direction, the resistance decreases). With the decrease in the thickness of the adhesive layer, the stability of the spine zone to the number of double flippers increases.

\section{Modeling of relationships between factors of influence on the strength of backed book blocks}

An important task of the technology of backing the spines of the blocks is to find the optimal process parameters. As a result of the analysis of the influence factors on the process of backing the book blocks, an oriented graph of relationships between them was developed taking into account the priority of influence (Figure 5). The isolated factors of influence are different in content. The influence of the individual factor has a weight, which was further taken into account for estimating the backing process of the block spine. The set of factors under consideration is a set $Z=\left\{z_{1}, z_{2}, \ldots, z_{n}\right\}$, from which one can define a subset $Z_{1} \in Z$ of the most significant criteria. At the vertices of the graph, we place the elements of subset $z$, and the arches connect the adjacent vertices $\left(z_{i}, z_{j}\right)$ for which a connection is defined, indicating the influence of the factor $z_{i}$ on the factor $z_{i}$. Thus, the physical and mechanical properties of the backing materials depend on the direction of the cutting of the backing material.

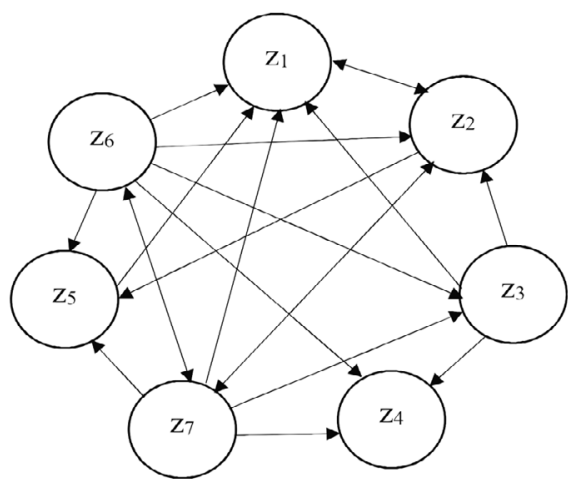

» Figure 5: A graph of relationships between the factors influencing the process of backing the spines of book blocks: $Z_{1}$ - the type of paper from which book blocks are made; $Z_{2}$ - the thickness of the book block; $Z_{3}-a$ way of backing (cold gluing, thermal bonding); $Z_{4}$ - the direction of cutting the backing material; $Z_{5}$ - the thickness of the backing material; $z_{6}$ - physical and mechanical properties of backing materials; $Z_{7}$ - the thickness of the adhesive layer
Based on the given relationship graph between the factors, a binary matrix of dependence and reach for a plurality of factors $Z$ was constructed, and the levels of factors hierarchy were determined. As a result, the probabilistic model of the hierarchy of factors of influence on the process of backing is synthesized. At the highest level of the hierarchy, the dependence of the strength of the backed block (expressed as efforts to break and to pull out of the sheet) on the thickness of the block and the type of backing material is located. This laid the foundation for further research.

Options for sticking the backing material to the spine of the block with different adhesives were considered. Hot-melt glue applying on a backing-captal braid implies warming it in the process of gluing to the spine of the block. Deformation properties of the backing-captal braid affect endurance to multiple flippers. The heating of a backing material with a glutinous layer does not reduce its resistance by repeated flipping. In the books, the line of bending of the backing material coincides with the longitudinal direction of the fibers, so the research backing materials can withstand the maximum number of bends, providing the necessary durability of the publication. Polyurethane adhesive within the relative extension of the backing materials provides a reduction in their deformation. At one and the same stress, the non-glue substrate deforms much more.

For an objective assessment of the influence of glues on the deformation properties of the backing material, with one axial tensile, a conditional coefficient of deformation $\mathrm{Kd}$ was introduced. This coefficient expresses the dependence of the stress $Q_{1}$, which deforms the backing material with a certain thickness of the coating $\Delta h$, to the corresponding stress value $Q_{0}$, which deforms the material without glue for the same value.

$\mathrm{K}_{\mathrm{d}}(\Delta \mathrm{h})=\mathrm{Q}_{1} / \mathrm{Q}_{0}$

Consequently, if the glue coating strengthens the spine of the block, for deformation of it of the same magnitude as the uncoated paper, the stresses $Q_{1} / Q_{0}>1$ are required. Thus, adhesives which provide $K \delta(\Delta h)>1$, strengthen the block in the spine, and at $K_{d}(\Delta h)<1$ - weaken it. The value of the coefficient of deformation of the backing materials with a pre-applied adhesive layer is presented in Table 2 .

\section{Table 2}

Coefficient of deformation of backing materials with applied adhesive layer

\begin{tabular}{l|l|l|l}
\hline $\begin{array}{l}\text { Material / direction } \\
\text { of cutting }\end{array}$ & $\begin{array}{l}\text { Polygraphic } \\
\text { gauze }\end{array}$ & $\begin{array}{l}\text { Kraft } \\
\text { paper }\end{array}$ & $\begin{array}{l}\text { Captal } \\
\text { braid }\end{array}$ \\
\hline Longitudinal direction & 1.21 & 1.14 & 1.31 \\
\hline Transverse direction & 1.71 & 1.30 & 1.89 \\
\hline
\end{tabular}


Table 3

Breakthrough efforts of the backing materials

\begin{tabular}{|c|c|c|c|c|c|}
\hline \multirow{3}{*}{$\begin{array}{l}\text { Kind of edging } \\
\text { material }\end{array}$} & \multirow{3}{*}{ Application method } & \multicolumn{4}{|c|}{ Direction of cutting } \\
\hline & & \multicolumn{2}{|c|}{ Transverse } & \multicolumn{2}{|c|}{ Longitudinal } \\
\hline & & $\mathrm{Z}, \mathrm{kH} / \mathrm{M}$ & $\mathrm{V}, \%$ & $\mathrm{Z}, \mathrm{kH} / \mathrm{M}$ & $\mathrm{V}, \%$ \\
\hline \multirow{2}{*}{ Captal braid } & With glue & 12.5 & 10.9 & 20.6 & 2.6 \\
\hline & Without glue & 12.0 & 10.2 & 18.3 & 2.5 \\
\hline \multirow{2}{*}{$\begin{array}{l}\text { Polygraphic } \\
\text { gauze (density } 15 \\
\text { threads } / \mathrm{cm} \text { ) } \\
\end{array}$} & With glue & 9.8 & 8.95 & 15.1 & 2.9 \\
\hline & Without glue & 9.2 & 8.55 & 14.9 & 2.7 \\
\hline \multirow{2}{*}{$\begin{array}{l}\text { Kraft paper } \\
\text { Swan White }\end{array}$} & With glue & 8.45 & 8.5 & 14.8 & 2.8 \\
\hline & Without glue & 8.3 & 8.1 & 13.8 & 2.7 \\
\hline
\end{tabular}

As a result of experimental studies, it was found that the strength of the book blocks depends on their thickness, the type of backing material (backing-captal braid, printing gauze and kraft paper Swat White), the direction of its cutting (transverse and longitudinal). The values of the breakthrough efforts of the backing materials are given in Table 3 .

Figure 6 shows the dependence of the breakthrough efforts of book blocks made of offset paper and backed by a captal braid on their thickness.
As can be seen, the longitudinal direction of cutting the backing-captal braid provides somewhat higher values of the breakthrough efforts of the blocks $(2.9 \mathrm{kN} / \mathrm{m})$ than the transverse direction $(2.75 \mathrm{kN} / \mathrm{m})$. With the increase in the thickness of the blocks from 2 to $7 \mathrm{~cm}$, the strength of the binding decreases by approximately 1.4 times.

It was found that the strongest are blocks of offset paper backed with a captal braid. The force of pulling a sheet from a block backed with a braid is $17.8 \mathrm{~N} / \mathrm{cm}$ (for blocks of offset paper) and $16.2 \mathrm{~N} / \mathrm{cm}$ (for blocks

a)

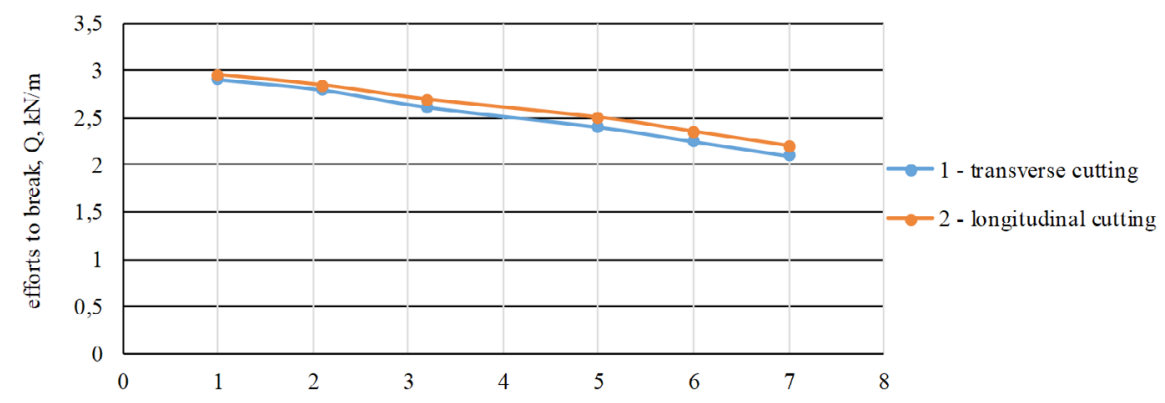

block thickness, $\mathrm{T} \cdot 10^{-2}, \mathrm{~m}$

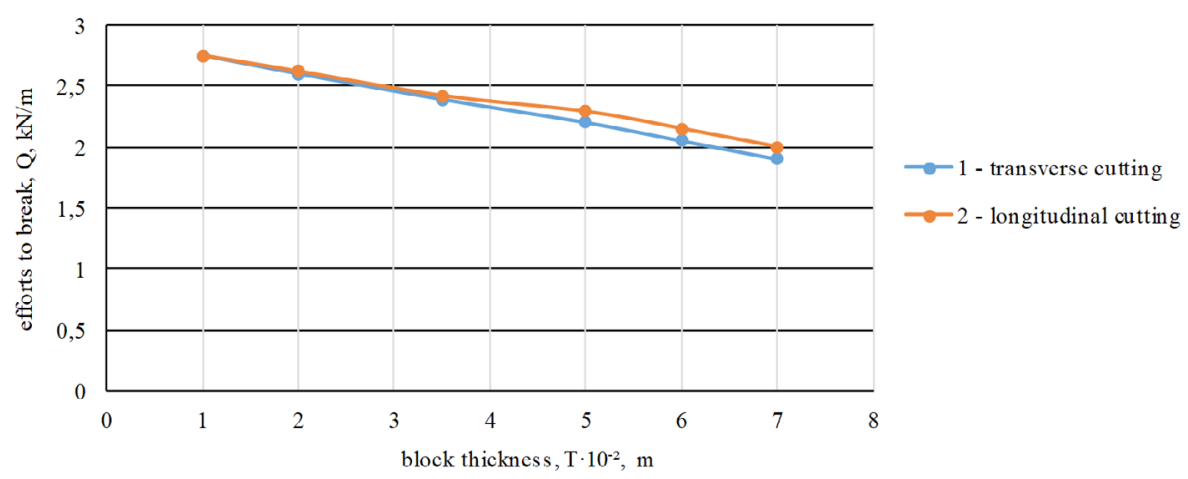

b)

" Figure 6: Dependence of the breakthrough effort (Q) of the book block made of offset paper on the thickness of the block (T), backed by a captal braid with a transverse (1) and a longitudinal (2) cutting: a - with an applied glue layer; $b$ - without glue 
of coated paper). Backing the spines of the blocks with a braid with longitudinal cutting, increases the effort of pulling the sheet from the block by 0.5-1 N/cm.

Different variants of linear models were tested for simulation of the dependence of breakthrough efforts. They have the following features:

$$
Q(S, Z, V)=A+B \cdot \phi_{T}\left(T_{b}\right)+C \cdot \phi_{Z}(Z)+D \cdot \phi_{V}(V)
$$

where $A, B, C, D$ - the unknown parameters of the model;

$\phi_{T}\left(T_{b}\right)$ - a function that describes the dependence of breakthrough efforts on the thickness of the block Tbl;

$\phi_{z}(Z)$ - a function that describes the dependence of breakthrough efforts on the direction of applied effort (longitudinal or transverse) Z;

$\phi_{V}(V)$ - a function that describes the dependence of breakthrough efforts on permissible elongation (longitudinal or transverse) $\mathrm{V}$.

$\mathrm{Q}(\mathrm{T}, \mathrm{Z}, \mathrm{V})$ - is the amount of breakthrough efforts, that taking into account the thickness of the block T; direction of applied effort Z; relative extension of the backing material $\mathrm{V}$.

The parameters A, B, C, D of the model were determined by the least squares method according to the criterion

$E=\sum_{i=0}^{n}\left(Q_{i}-Q\left(T_{b(i)^{2}} z, v\right)\right)^{2} \rightarrow \min$

where $\mathrm{n}$ - the number of experimentally recorded observations of breakthrough efforts at different thicknesses of the book blocks $T_{b l(i)}$.
Among the considered functions, different types of dependencies were tested, in particular, logarithmic, degree and index. Of all tested for the mean square criterion of the models variants of the form (2), the least value of the sample deviation average (3) was observed with the application of a linear dependence of the form

$Q\left(T_{b P} Z, V\right)=A+B \cdot T_{b l}+C \cdot Z+D \cdot V$

When constructing models of breakthrough efforts of the enclosed book blocks $(Q)$, the thickness of the block $\left(T_{b}\right)$, relative elongation $(V)$ of the backing materials in the transverse $\left(Z_{h}\right)$ and longitudinal $\left(Z_{1}\right)$ directions of cutting were taken into account. As a result of the study of book blocks backed with captal braid, gauze and kraft paper, it was discovered that the nature of the breakthrough effort of the block depends on its thickness, types of paper and the backing material and the direction of the cutting of the backing materials (Table 4).

Thus, the obtained dependence models of breakthrough efforts and the efforts of pull out the sheet from the block of thickness confirm the expediency of the backing operation in order to strengthen the spines of the book and ensure the compliance of the performance indicators with the norms of the International standards of the ISO.

\section{Conclusions}

1. It has been established that adhesives influence the deformation properties of the backing material. So, the non-glue substrate deforms much more than with the applied glue layer. The maximum coefficient of deformation has a braid in the transverse direction- 1.89 and in the longitudinal-1.31, the

\section{Table 4}

Models of breakthrough efforts of backed book blocks

\begin{tabular}{|c|c|c|c|c|}
\hline $\begin{array}{l}\text { The paper from } \\
\text { which the book } \\
\text { blocks are made }\end{array}$ & $\begin{array}{l}\text { The type of } \\
\text { backing material }\end{array}$ & $\begin{array}{l}\text { Direction } \\
\text { of cutting }\end{array}$ & $\begin{array}{l}\text { Models of breakthrough efforts } Q_{h}[\mathrm{kH} / \mathrm{M}] \text {, and } \\
\text { pull out the sheet from block } P_{h}[N / \mathrm{cm}]\end{array}$ & $\begin{array}{c}\text { Medium-quadratic } \\
\text { deviation }\end{array}$ \\
\hline \multirow{4}{*}{ Offset } & $\begin{array}{l}\text { Braid Gauze } \\
\text { Kraft paper }\end{array}$ & transverse & $Q_{h}\left(T_{b p^{\prime}}, Z_{h}, V_{h}\right)=2,43354-0,14133 \cdot T_{b l}+0,17973 \cdot Z_{h}-0,14132 \cdot V_{h^{\prime}}$ & 0,081 \\
\hline & \begin{tabular}{|l|} 
Braid Gauze \\
Kraft paper
\end{tabular} & longitudinal & $a_{1}\left(T_{b l}, Z_{1}, V_{1}\right)=2,73061-0,12533 \cdot T_{b 1}+0,049295 \cdot Z_{1}-0,215662 \cdot V_{1}$ & 0,078 \\
\hline & \begin{tabular}{|l|} 
Braid Gauze \\
Kraft paper
\end{tabular} & transverse & $P_{h}\left(T_{b l}, Z_{h}, V_{h}\right)=9,58911-0,44295 \cdot T_{b l}+1,092303 \cdot Z_{h}-0,50595 \cdot V_{h}$ & 0,27 \\
\hline & $\begin{array}{l}\text { Braid Gauze } \\
\text { Kraft paper }\end{array}$ & longitudinal & $P_{1}\left(T_{b \prime}, Z_{1}, V_{1}\right)=8,6171-0,444857 \cdot T_{b 1}+0,489829 \cdot Z_{1}-0,167083 \cdot V_{1}$ & 0,49 \\
\hline \multirow{4}{*}{ Coated } & $\begin{array}{l}\text { Braid Gauze } \\
\text { Kraft paper }\end{array}$ & transverse & $Q_{h}\left(T_{b l}, Z_{h}, V_{h}\right)=1,99266-0,13619 \cdot T_{b 1}+0,13757 \cdot Z_{h}-0,07073 \cdot V_{h}$ & 0,067 \\
\hline & \begin{tabular}{|l} 
Braid Gauze \\
Kraft paper
\end{tabular} & longitudinal & $Q_{1}\left(T_{b}, Z_{h}, V_{h}\right)=2,0591-0,12962 \cdot T_{b 1}+0,05525 \cdot Z_{h}-0,0771 \cdot V_{h}$ & 0,081 \\
\hline & $\begin{array}{l}\text { Braid Gauze } \\
\text { Kraft paper }\end{array}$ & transverse & $P_{h}\left(T_{b l}, Z_{h}, V_{h}\right)=11,83287-0,48666 \cdot T_{b l}+2,069135 \cdot Z_{h}-2,06997 \cdot V_{h}$ & 0,59 \\
\hline & $\begin{array}{l}\text { Braid Gauze } \\
\text { Kraft paper }\end{array}$ & longitudinal & $P_{1}\left(T_{b p^{\prime}} Z_{1}, V_{1}\right)=22,91415-0,4321 \cdot T_{b 1}+0,3011021505 \cdot Z_{1}-5,2234 \cdot V_{1}$ & 0,16 \\
\hline
\end{tabular}


minimum kraft paper-1.14- in the longitudinal direction and 1.5 in the transverse. With the growth of the deformation of stretching of the backing materials from $1.2 \%$ (for kraft paper) to $3.8 \%$ (for the captal braid), the stability of the spine zone of the block increases to damage in the process of multiple flippers. The investigated materials in the longitudinal direction are more durable than in the transverse 2-2.5 times, so the enclosed blocks can withstand 2490 to over 3000 flippers when using kraft paper and backing braid, respectively.

2. The factors of influence on the process of backing the spine of the block are determined and an oriented graph of connections between them is developed. As a result of simulation of the dependence of breakthrough efforts, linear models are obtained, the functions of which describe the dependence of breakthrough efforts on: the thickness of the block; direction of applied efforts (longitudinal or transverse); permissible elongation (longitudinal or transverse) of the backing material.

3. It was established that the strongest are blocks from offset paper backed with a captal braid. Efforts to break the blocks backed with a braid with a transverse cutting is $-2.7 \mathrm{kN} / \mathrm{m}$, and with a longitudinal $-2.95 \mathrm{kN} / \mathrm{m}$. Backing the spines of the blocks with a braid with longitudinal cutting, increases the effort of pull out the sheet from the block by $0.5-1 \mathrm{~N} / \mathrm{cm}$. With an increase in the thickness of the blocks from 2 to $7 \mathrm{~cm}$, the strength of the binding decreases by about 1.4 times.

\section{References}

Anon (1998) Binden und Falzeln leicht gemacht. Bindereport. 5, p. 64.

Bubela, R \& Shabliy, I. (2016) Research of book block strength manufactured using hot melt adhesives. Book Qualiology. 2 (30), 36-40. Available from: https://www.uad.Iviv.ua/naukovi-vydannia/52-kvalilohiia-knyhy/233-arkhiv-vydannia-kvalilohiia-knyhy

Dyakonov, V. (1998) Mathematical system Maple V R3 / R4 / R5. Moscow, Solon-Press Publisher, p. 399.

Fischer, U. \& Naber, A. (2006) Near-field optics-light microscopy for nanoscience. Photonik international. 5, 82- 85.

Gromyko, I. \& Marchenko, I. (2018) The influence of the structure of materials on the formation of adhesive seam and cohesive strength of the adhesive layer in the spine of the block. Proceedings of BSTU 2018- Print and Media. 4 (1), 14-19.

Havenko, S., Durnyak, B., Bernatsek, V. \& Kadyliak, M. (2018a) Modeling of Stress-Strained State of the Block Spine During the Exploitation of Book and Magazine Editions. MECHANIKA 2018: Proceedings of 23rd International Conference, MECHANIKA 2018, 18 May 2018, Kaunas, Lithuania. Kaunas, Kaunas University of Technology. pp. 41-46.

Havenko, S., Labetska, M., Ohirko, O. \& Mykhaylyshyn, G. (2018b) Badanie czynnikuw wplywajencych na wytrzymalosc polonczen klejowych wkladuw ksionzek. Przryglond Papierniczy. 1 (9), 586-590.

Havenko, S. F., Kulik, L.Y., Martynyuk, M.S. \& Konyukhova, I.I. (1998) The method of backing the spine of the book blocks. UA24581 (Patent).

Knysh O. (2013) Technology of book shelfback preparation is offered to the pasting-up at the glue cleating. Technological complexes. 2 (8), 95-99.

Kolpakova I. (2003) Everything is glued together! Or how to fasten the block on the back?. Kursiv. 4. Available from: http://www.kursiv.ru/kursivnew/ kursiv_magazine/archive/42/38.php\#text

Palyuk O. (2018) Experimental determination of the influence of adhesives on the formation of natural angles of opening of book blocks. Technology and technique of printing. 1 (59), 37-41.

Petriaszwili, G. Pyrjew, Y. (2008) Analysis of a model of the adhesive layer between two sheets of paper. Journal of Vibroengineering. 10 (3), 282-284.

Petrie, E.M. (2008) Bookbinding Adhesives. ASI Magazine. Available from: https://www.adhesivesmag.com/articles/87133-bookbinding-adhesives [Accessed 20th December 2019].

Polit, N., Snowden, D. \& Watson, D. (1974) Apparatus and method for binding a stack of sheets. US3788921A (Patent).

Rabinovich, A., I. (1998) Up Perfect way to perfect binding of books. RU98104572A (Patent).

Stachowicz S. (2013a) Selection of the materials for back of cover reinforcement on the base of the energy absorption criterion. Przegląd Papierniczy. 69 (4), 241-246.

Stachowicz, S. (2013b) Tests on/ usability of materials for spine reinforcement. Przegląd Papierniczy. 69 (10), 539-545.

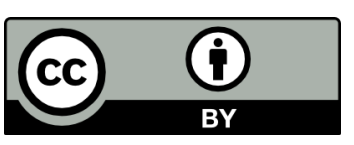

(C) 2020 Authors. Published by the University of Novi Sad, Faculty of Technical Sciences, Department of Graphic Engineering and Design. This article is an open access article distributed under the terms and conditions of the Creative Commons Attribution license 3.0 Serbia (http://creativecommons.org/licenses/by/3.0/rs/). 